\title{
O VERMELHO E O NEGRO: UM EXPERIMENTO PARA PENSAR O RITUAL*
}

Michael Houseman

Com o objetivo de explorar a ação ritual enquanto tal ("em si e por si", como recomenda Lévi-Strauss [1971:598]), tenho submetido meus alunos e demais participantes de um seminário que dirijo na École Pratique des Hautes Études a um algo descarnado rito de iniciação masculina, de minha própria autoria: O Vermelho e o Negro. Proponho-me aqui a descrevê-lo, sugerindo, ao mesmo tempo, certos traços recorrentes da ação ritual e, especificamente, dos ritos de iniciação (masculina).

\section{Introdução}

Esse experimento foi projetado para ilustrar, e fundamentar melhor, idéias que desenvolvi alhures no contexto de uma abordagem analítica particular, que chamei "relacional", da performance ritual (cf. Houseman e Severi 1998; Houseman 1993; 2000; 2002). Nos termos desta abordagem, o ritual é visto como atuação [enactment] de relações, sejam elas relações entre participantes humanos ou, ainda - embutidas em uma rede de laços interpessoais —, relações com entidades outras, não humanas: espíritos, deuses, ancestrais, animais, objetos, fórmulas litúrgicas e assim por diante. Na medida em que essas relações são atuadas [acted out] e não apenas referidas, elas constituem não conexões lógicas ou metafóricas entre termos ou categorias abstratas, mas experiências pessoais sustentadas por eventos intencionais e emocionalmente carregados. Todavia, as relações que as pessoas atuam no ritual são, sob vários aspectos, inusitadas. Primeiro, ao reunirem em uma única seqüência de ação aspectos extraídos de uma grande variedade de domínios (subsistência, ciclo de vida, parentesco, outros eventos cerimoniais etc.), as relações rituais reenquadram esses elementos heteróclitos como componentes in- 
terdependentes de uma nova totalidade experienciada, a saber, a própria performance ritual. Assim, elas não são apenas altamente evocativas, mas também extraordinariamente integrativas.

Em segundo lugar, as relações rituais envolvem, caracteristicamente, aquilo que eu e Carlo Severi (1998) chamamos "condensação ritual", ou seja, a atuação simultânea de modos de relação formalmente contrários: afirmações de identidade são ao mesmo tempo testemunhos de diferença; exibições de autoridade são também demonstrações de subordinação; a presença de pessoas ou outros seres é ao mesmo tempo corroborada e negada; segredos são simultaneamente dissimulados e revelados, e assim por diante. Ao incorporarem tais situações singulares, as performances rituais são imediatamente reconhecíveis como distintas da interação cotidiana: não é possível dar conta delas em termos de intencionalidades e padrões relacionais ordinários.

Terceiro, essas performances aparentemente anômalas são vistas como carregadas de significado (as conseqüências pragmáticas e qualidades afetivas da experiência ritual desempenham aí um papel importante), na medida em que são postas entre parênteses, isto é, sustentadas por um grau de auto-referência que lhes confere uma autoridade relativamente indiscutível. As performances aparecem como repetições necessárias, em lugar de invenções arbitrárias. A ritualização pode assim ser pensada como um processo de recontextualização, cujo caráter "privilegiado" (Bell 1992) deriva da combinação dessas três propriedades: é um processo experiencialmente fundado, altamente integrativo e, devido à associação sistemática de modos de relação normalmente antitéticos, difícil de definir em termos outros que sua própria atuação ${ }^{1}$.

Essa perspectiva envolve uma quantidade de questões complexas, dentre as quais quero abordar aqui apenas uma, a da eficácia ritual. Compreendo a eficácia ritual como algo referente à produção — depois e para além da performance do rito em si - de comportamentos e discursos que pressupõem as relações atuadas durante sua execução. A ocorrência desses elementos de fala ou ação pode ser tomada como uma indicação do grau de comprometimento dos participantes com a realidade das relações rituais que atuam. A ação ritual, se eficaz, afeta assim irreversivelmente a interação ordinária de modo evidente: o antes e o depois não são o mesmo. Desse ponto de vista, ritualização é um negócio sério; sua eficácia é bastante diferente da gratificação resultante do participar de ou assistir a um jogo ou um espetáculo.

Minha hipótese de trabalho é que a eficácia distintiva do rito deriva, antes de tudo, não de seu simbolismo substantivo, nem de suas conse- 
qüências pragmáticas, nem, enfim, de suas qualidades performativas, mas da própria atuação das relações especiais que sua execução envolve. Minha intenção ao conceber o experimento ora descrito foi, pois, projetar um ritual que consistisse essencialmente, senão exclusivamente, em um padrão particular de interação: O Vermelho e o Negro não pertence a nenhuma tradição cultural reconhecível, não envolve quase nenhum simbolismo explícito, suas "crenças" subjacentes são abertamente despropositadas, suas qualidades cênicas mínimas e não se pode atribuir a ele praticamente nenhuma função social.

Devo esclarecer de saída que o que vou descrever, em sua maior parte, não foi pensado de antemão. Ainda que baseados em anos de estudo de ritos de iniciação masculina, os "design features" (Handelman 1998) de O Vermelho e o Negro vieram à luz mais ou menos de uma só vez, de maneira largamente intuitiva. Eu buscava algo tão simples quanto possível, mas cujas propriedades emergentes, autolegitimadoras, capturassem o que eu sentia constituir a essência da iniciação: um processo discriminativo, atribuidor de identidade, cujos produtos (os iniciados) constituem os meios de sua própria reiteração (cf. Zempléni 1991). Basicamente, procurei envolver as pessoas em uma experiência interativa incontestável, mas difícil de conceitualizar, cujo ponto de partida ostensivo e arbitrário (a diferença entre masculino e feminino) se tornasse, para os participantes, uma discriminação natural e irrefutável, definida em termos dessa experiência e da distinção convencional (entre iniciados e não-iniciados) por ela produzida (cf. Bourdieu 1986). Evidências da eficácia de $\mathrm{O}$ Vermelho e o Negro como ritual foram buscadas na ocorrência subseqüente de falas ou comportamentos compatíveis com esse processo paradoxal de redefinição. Embora eu obviamente não esperasse um compromisso duradouro da parte dos participantes, meu interesse era verificar o quanto seria detectável algum efeito nessa direção, mesmo que sutil. Por exemplo, estava particularmente atento para atos e discursos espontâneos sugestivos de que as mulheres não tinham acesso aos mistérios de $\mathrm{O}$ Vermelho e o Negro não porque não fossem iniciadas, mas porque eram mulheres. A afirmação é certamente verdadeira no contexto de meu ritual inventado: apenas os homens são iniciados. Entretanto, o que estou sugerindo é que a eficácia deste (e de qualquer outro) rito reside precisamente no fato de que, como resultado da performance, afirmações desse tipo passam a ser aplicadas para além do quadro ritual, sendo abertamente sustentadas como proposições não sobre o rito, mas sobre o mundo. 


\section{Preparação}

Os participantes são prevenidos (geralmente com uma semana de antecedência) de que serão submetidos a um rito de iniciação. Digo-lhes que são os homens que passarão pelo ritual, mas que as mulheres também participarão: na realidade, afirmo, a participação de todos é essencial para que o ritual "funcione". Freqüentemente, menciono a possível presença de alunos que já teriam passado por O Vermelho e o Negro e que seriam capazes, portanto, de guiar os recém-chegados; caso ninguém se encontre em tal situação, esclareço, não importa, pois darei eu mesmo as instruções necessárias².

No dia em que a iniciação deve realizar-se, penduro uma cortina em um dos cantos da sala, próximo à área onde se concentrará a maior parte da ação. Abro a aula ou seminário introduzindo o ritual. Se, pelo menos de início, nunca comecei declarando ter inventado O Vermelho e o Negro, meu relato nesse momento deixa isso bastante óbvio. Escrevendo "Le Rouge et le Noir" no quadro, explico que se trata, na verdade, de um ritual norte-americano, mas de origem franco-belga (ainda que não mais praticado na França ou Bélgica). Assim, explico, se podem encontrar várias referências oblíquas a ele na cultura francófona: menciono Stendhal (a maior parte dos estudantes franceses leu ou ouviu falar de Le Rouge et le Noir), Jacques Brel (o célebre compositor belga que cantava sobre o vermelho e o negro) e o banco Société Générale (cujo logotipo é composto de um retângulo preto sobre um vermelho). Essa origem franco-belga explicaria o fato de que a língua usada durante a performance será o francês e não o inglês; assim, concluo, uma vez começado o ritual, apenas a primeira língua deverá ser utilizada (nunca, é claro, outra língua é utilizada em minhas aulas).

Um dos problemas postos por esse experimento é o do enquadramento [framing]: a auto-instauração de um quadro ou contexto ritual é extremamente difícil. O ponto de partida desse exercício é implicitamente uma situação de jogo ("vamos brincar de fazer um ritual"). Todavia, se os participantes passassem por O Vermelho e o Negro com a idéia de que estão apenas brincando ou fingindo, a performance perderia sua eficácia como ritual: ninguém esperaria que tivesse qualquer efeito real na vida ordinária ${ }^{3}$. Meu problema, portanto, é: como fazer $\mathrm{O}$ Vermelho e o Negro "sério" o suficiente? Minha autoridade como professor ajuda, mas apenas até um certo ponto, pois os alunos são meus cúmplices na natureza experimental dessa iniciativa. Em outras palavras, fico prisioneiro de um dilema: se não levo O Vermelho e o Negro a sério, os outros participantes também não o farão; mas se eu o levo 
realmente a sério, eles não me levarão a sério, e a coisa se torna apenas mais um jogo.

A solução que adotei foi tratar proposições patentemente absurdas com uma gravidade obviamente fingida, colocando em questão a natureza lúdica do empreendimento por meio de uma dupla negativa. Proponho um experimento ritual em lugar de uma experiência ritual. Em outras palavras, em lugar de simular uma performance ritual verdadeira, finjo simular uma performance falsa. Ao fazê-lo, meu objetivo é solapar o quadro lúdico, tornando as regras ou convenções subjacentes ao reconhecimento de uma atividade qualquer como jogo abertamente confusas e, idealmente, ao mesmo tempo constitutivas e autocontraditórias (cf. Houseman e Severi 1998). Por meio de um tal questionamento implícito do quadro, tento estabelecer o caráter excepcional do empreendimento, mantendo ao mesmo tempo obscura sua exata natureza: é preciso participar de O Vermelho e o Negro para compreender de que tipo de atividade realmente se trata. Assim, minha explicação, claramente ridícula, do ritual como sendo de origem americana ou franco-belga associa-se, de modo espúrio, a referências reais e à minha inegável identidade de americano transplantado para a França, ligada à minha autoridade como professor. Da mesma maneira, a origem supostamente francófona do rito permite-me introduzir o imperativo absurdamente redundante de se falar francês durante sua performance. Para introduzir todo esse blablablá, escrevo THE RED AND THE BLACK no quadro. Este gesto, rebarbativamente didático (como o foram as referências a Stendhal, Brel e ao banco Société Générale), é ao mesmo tempo enganador, pois, como veremos, um dos segredos do ritual joga com a homonímia aproximada das palavras francesas et (e) e est (é): ao escrever o nome do rito em inglês (o que se justifica por tratar-se de um ritual americano), estabeleço et (e) como a interpretação natural ou default da frase quando falada em francês.

Solicitando aos homens que deixem a sala, dou instruções, primeiro às mulheres e depois a eles lá fora, sobre como executar o ritual. Às primeiras, explico que devem permanecer sentadas juntas, numa das extremidades da sala. Os homens serão trazidos um a um e instruídos a sentar-se a uma mesa, voltados para as mulheres no outro canto, cerca de seis metros de distância; eu mesmo, o iniciador, sentarei à mesma mesa diante do noviço, de costas para as mulheres. As mulheres devem manter-se em silêncio enquanto o noviço é trazido para dentro. Todavia, uma vez este sentado, devem começar a murmurar para si mesmas (podem dizer o que bem entenderem), alto apenas o suficiente para que não possam ouvir o que vou dizer ao noviço. É 
importante, advirto, que não escutem o que está sendo dito, mas é também importante que prestem atenção detalhada à performance do noviço, pois ao fazê-lo o estarão apoiando durante o rito. Digo-lhes ainda que, em um certo momento, o noviço irá gritar. Quando isto acontecer, elas devem cessar o murmúrio e, ou aclamar o iniciando ou (em algumas performances) suspirar, bem alto, de alívio. Finalmente, explico-lhes que o noviço anunciará em voz alta: "le rouge et le noir" ("o vermelho e o negro"), e que elas devem responder, no mesmo volume: "oui, le rouge et le noir" ("sim, o vermelho e o negro").

Aos homens, explico que serão trazidos para dentro individualmente. Enquanto um passa pelo rito, os que estão à espera devem permanecer no corredor. Como a porta ficará parcialmente aberta, serão capazes de ouvir o que se passa; todavia, não devem olhar, pois isso prejudicaria o ritual. Acrescento freqüentemente que, de qualquer maneira, não há mesmo nada para se ver. Finalmente, explico-lhes que devem fazer o que eu disser ou o ritual não "funcionará" direito.

De modo a estabelecer as bases para o comprometimento dos participantes com as realidades rituais que atuarão, não forneço nem aos noviços nem às mulheres uma descrição completa do processo de iniciação, mas apenas informação suficiente para que assumam adequadamente seus respectivos papéis. Impedindo os participantes de conceitualizar o ritual de modo distanciado, encorajo-os a experenciá-lo diretamente, forçando-os a adotar pontos de vista particulares em relação uns aos outros no contexto da performance. Ao mesmo tempo, minhas instruções almejam promover uma articulação harmoniosa de suas ações, de modo que uma dinâmica geral possa emergir. Assim, a apreensão do ritual como uma totalidade distintiva não é proporcionada aos participantes previamente, mas por eles constituída progressivamente de maneira pessoalmente motivada: uma apreensão derivada de suas próprias percepções e comportamentos, tais como ditados por sua interação coordenada.

Levo mais tempo com as mulheres, às quais atribuo mais responsabilidade do que aos noviços. Estes, deixados em boa parte "no escuro", se tornam claramente dependentes daquilo que eu, o iniciador, lhes direi, enquanto as mulheres, melhor informadas sobre o que acontecerá, são entretanto obrigadas, como outsiders, a esperar a deixa dos noviços. Isso cria uma tensão interessante, que opera como um incentivo implícito para a performance ritual: de um lado, as mulheres presumem que os noviços (supostamente, conhecedores do segredo) foram providos com informações privilegiadas, quando, de fato, não o foram; de outro lado, os 
noviços, cientes o tempo todo de que as mulheres são a parte ostensivamente excluída, não podem deixar de notar que, na realidade, talvez elas saibam mais do que indica seu comportamento. O desconforto inerente a essa situação é aumentado pelo fato de que, uma vez iniciado o ritual, as mulheres são capazes de ver, mas não de ouvir, o que se passa do outro lado da sala, enquanto os noviços, esperando lá fora, são capazes de ouvir o murmúrio das mulheres, mas não podem ver a parte que estas desempenham. Essa tensão é ainda acentuada pelas negociações silenciosas que invariavelmente se dão entre os noviços no que toca à ordem em que serão iniciados, e entre as mulheres quanto a estarem ou não seguindo corretamente suas instruções. Finalmente, deve ser notado que essa tensão se desfaz imediatamente quando qualquer comunicação visual, mesmo ínfima, ocorre entre as mulheres e os noviços no corredor (em uma ocasião infeliz, que prejudicou significativamente a solenidade do rito, havia uma porta de vidro permitindo a alguns noviços ver que as mulheres viam que os noviços podiam vê-las).

Nas duas últimas vezes que organizei O Vermelho e o Negro, após dar as instruções, convidei os homens de volta à sala para participar com as mulheres de um exercício preparatório. Neste exercício, faço com que todos se sentem, pedindo que coloquem suas mãos sobre a mesa em frente, fechem os olhos, relaxem e fiquem à vontade. Faço o exercício com eles. Peço-lhes (explicando que alguns talvez achem mais fácil fazê-lo voltando a cabeça para um lado) que emitam um som fino, lamuriento, um gemido, alto apenas o suficiente para que só eles mesmos o escutem. Depois de mais ou menos trinta segundos, digo que mantenham os olhos fechados e as mãos sobre a mesa, mas levantem a cabeça e abram a boca o máximo possível. "Abram mais", digo, "mais que isso!", "mais ainda!". Peço, então, que mantenham os olhos fechados e imaginem que suas mãos estão presas na mesa de modo que, por mais que o tentem, não conseguem movê-las. Depois de um minuto, digo-lhes que podem mexer a cabeça. Finalmente, declaro o exercício terminado.

Esse exercício preliminar é útil, pois estabelece o padrão para o que, de várias maneiras, constitui a essência da experiência ritual. Os participantes vêem-se pessoalmente envolvidos em ações corporais prescritas, emocionalmente carregadas, cujo significado exato permanece, todavia, obscuro. A suposição pragmática que governa intuitivamente a interação ordinária - ações visíveis expressam sentimentos e intenções privados é invertida: nos quadros desse exercício preparatório, é o comportamento 
estipulado dos participantes que se torna a fonte de sua experiência individual. A natureza exata dos sentimentos induzidos pela obrigação de gemer para si mesmo, de abrir forçadamente a boca, de agir como se as mãos estivessem grudadas na mesa etc. é desimportante, e permanece, suponho, em grande medida, uma função da personalidade de cada participante. De fato, o exercício, mobilizando um amplo leque de emoções possíveis (autopiedade, frustração, estresse, alívio), é projetado para deixar uma boa margem de liberdade para o envolvimento individual, de modo que cada participante possa fazer sua essa experiência coletivamente imposta (O que eu deveria estar sentindo? Como exatamente devo gemer? Quando precisamente devo fechar a boca? etc.). Significativamente, muitos usam esse exercício para tentar compreender o que vai se seguir. Os noviços especulam nesse sentido enquanto aguardam no corredor; alguns admitem depois ter esperado que o ritual fosse ligado ao exercício (há, por exemplo, os que passam o rito inteiro com as mãos espalmadas sobre a mesa). Mais uma vez, assim como o crucial não são os estados afetivos específicos eventualmente suscitados pelos atos dos participantes, mas o fato de que estes atos estão investidos de intencionalidade e afeto (a animosidade é bem-vinda, a indiferença não), o que parece contar, quanto ao comprometimento dos participantes com o ritual, são menos as interpretações precisas que eles possam fazer de seu comportamento que sua pressuposição de que este é dotado de significado.

\section{Performance}

Uma vez finalizado o exercício preparatório, convido homens e mulheres a tomarem seus respectivos lugares para dar início ao ritual. Enquanto as pessoas se posicionam, coloco uma caixa preta e outra vermelha, uma ao lado da outra, na mesa localizada na extremidade da sala oposta àquela onde se sentam as mulheres. As caixas são altas o suficiente para que o noviço, quando sentado (a caixa preta à sua esquerda), não possa enxergar seu conteúdo. Um pano branco cobre a área da mesa entre as caixas e a cadeira a ser por ele ocupada, e sobre este pano está uma pequena ficha branca sobre a qual coloco meus óculos de leitura. Sento-me do outro lado da mesa, de costas para as mulheres, de frente para a cadeira do noviço. Quando todos estão em silêncio, levanto-me, viro-me e anuncio que o ritual vai começar.

Vou até o corredor e convido o homem mais próximo da porta para entrar (quando há um iniciado presente, quer dizer, um homem que já tenha passado pelo ritual, instruo-o a fazer isso por mim). Indico ao noviço que deve sen- 
tar-se à mesa, na cadeira voltada para as mulheres, e me sento face a face com ele. As mulheres começam a murmurar. Mantendo o máximo de contato visual possível, dou ao noviço as boas-vindas a O Vermelho e o Negro. Informolhe que irei pedir que coloque sua mão na caixa preta, e que ele sentirá algo lá dentro. Todavia, independente do que sentir, seu rosto deve permanecer completamente impassível. Digo-lhe que, enquanto estiver fazendo isso, deve ler para si o que está escrito na ficha posta à sua frente (em maiúsculas: LE ROUGE ET LE NOIR [o vermelho e o negro]). Tiro meus óculos de cima da ficha e digo-lhe para colocar a mão esquerda na caixa preta. "Você está sentindo alguma coisa?", pergunto. "Continue procurando: está sentido algo, agora?". O noviço, mantendo-se sério, indica que sim (pois de fato, no fundo da caixa, sente algo líquido e ligeiramente gosmento). Revelo que, antes do começo da aula, cuspi abundantemente na caixa, e que o que ele está tocando é a minha saliva. Ele luta para controlar o nojo. Quando o noviço tira a mão de dentro da caixa (freqüentemente limpando-a no pano branco sobre a mesa), viro o cartão e, outra vez, coloco meus óculos sobre ele. Falo então que vou pedir-lhe que ponha a mão direita na caixa vermelha, e que ele deve tentar pegar o que está lá dentro (dando a entender que se trata de algo vivo). Isso, explico, pode doer um pouco, mas só um pouco (dentro da caixa vermelha há um pequeno cacto). No momento em que tocar o conteúdo da caixa, porém, ele deve gritar muito alto e, ao mesmo tempo, ler para si mesmo o que está escrito no verso do cartão (agora: LE ROUGE EST LE NOIR [o vermelho é o negro]). Tiro meus óculos de cima do cartão e digo que coloque a mão dentro da caixa vermelha. Quando o noviço sente os espinhos da planta (alguns a agarram fortemente, enquanto outros apenas a tocam), grita como se sentisse muita dor. As mulheres aclamam-no ou soltam um profundo suspiro de alívio. Feito isso, peço em voz alta que o noviço proclame o mistério do ritual, indicando com os olhos o cartão diante dele. O noviço anuncia: "O vermelho é o negro", ao que as mulheres respondem, como instruídas, "Sim, o vermelho e o negro". Eu então aperto as mãos do noviço, congratulo-o por ter passado por O Vermelho e o Negro, e o convido a retirar-se para o canto da sala atrás da cortina, onde deve permanecer virado para a parede e sem espiar para fora.

O próximo noviço é trazido para dentro e o processo recomeça. Quando o último acabou de passar por tudo e estão todos atrás da cortina, peço aos homens que saiam e, encarando conjuntamente as mulheres, proclamem mais uma vez o "mistério": "O vermelho é o negro". As mulheres, ao meu sinal, respondem de novo: "Sim, o vermelho e o negro". Finalmente, solicito a todos que repitam ainda uma vez, agora juntos: "Sim, o vermelho e/é o negro". Indico que o ritual terminou, e que teremos agora um intervalo de cinco minutos. 
Um de meus objetivos ao projetar esse ritual foi envolver os participantes em um comportamento convencional no qual atitudes e relações contrárias se combinassem inextricavelmente. Assim, as ações que os participantes são levados a realizar mostram-se conceitualmente incertas: facilmente reconhecíveis como distintas da interação cotidiana e difíceis de definir em termos outros que sua própria atuação. Lançando mão de um traço recorrente dos ritos de iniciação masculina (cf. Cohen 1964), coloquei as mulheres em uma situação comunicativa paradoxal: é porque interagem com os homens (estão conscientes de que eles escutam seu murmúrio) que elas estão separadas deles (o murmúrio as impede de escutar o que iniciador e noviço estão dizendo). Essa posição ambígua é tanto mais difícil quanto são as próprias mulheres que precisam determinar, a partir do nível de ruído produzido em volta da mesa, quão ruidoso dever ser seu próprio murmúrio. Durante o rito, elas freqüentemente entreolham-se, verificando a adequação do rumor que produzem (as que já participaram em performances anteriores tendem a dar o tom). Além disso, como elas foram instruídas a prestar cuidadosa atenção ao comportamento dos noviços, torna-se-lhes extremamente tediosa a obrigação de murmurar continuamente enquanto o fazem. Assim, suas frases reduzemse rapidamente a uma seqüência de sílabas sem sentido, misturando-se em uma espécie de ressonância verbal coletiva que adquire espontaneamente uma qualidade semimusical.

Os noviços também são postos em uma situação contraditória diante das mulheres que os observam. Devem expressar, em momentos alternados, bem mais e bem menos do que estão efetivamente sentindo: se precisam controlar o nojo ao ouvir que tocavam minha saliva na caixa preta, têm que exagerar abertamente a dor decorrente do contato com o cacto na caixa vermelha. Incapazes de disfarçar sua ansiedade quanto às provas a que são submetidos, devem ao mesmo tempo dissimular seu desapontamento ante o caráter relativamente inócuo dessas provações. O segredo revelado aos noviços (o conteúdo das caixas) é decepcionantemente trivial, e este fato, tanto quanto a natureza daqueles conteúdos, constitui o segredo com o qual estão comprometidos. Há, é claro, ainda um outro nível de sigilo que os noviços devem, ao mesmo tempo, reconhecer para si mesmos e ocultar das mulheres: ao contrário do que possam pensar os não-iniciados, eles na verdade não sabem o que as caixas contêm. Sobre a caixa preta, sabem apenas o que lhes conto (e minto: não se trata de saliva, mas de clara de ovo misturada com água); sobre a vermelha, podem apenas fazer suposições baseadas em uma vaga sensação tátil (sugiro haver algo vivo lá dentro, mas isso não é inteiramente verdade). 
Assim, boa parte dos noviços, uma vez terminada a iniciação, tenta olhar dentro das caixas; eu, é claro, não permito. Dessa maneira, a revelação de um conhecimento privilegiado, iniciático, é ao mesmo tempo um ato de ocultamento, tanto da parte dos noviços em relação às mulheres, como do iniciador em relação aos próprios noviços. Finalmente, acentuo o estado excitado e desorientado dos noviços pedindo que façam várias coisas ao mesmo tempo: colocar a mão no interior da caixa, reagir de uma maneira determinada e forçada ao que sentem, ler o cartão à sua frente e ouvir o que lhes digo, tudo isso com o murmúrio variável das mulheres ao fundo. Com sorrisos fixos, nervosos, ou faces sem expressão, olhamme nos olhos o tempo todo. É efetivamente essencial que a provação dos noviços, embora breve, seja ao mesmo tempo complexa e bastante desafiadora; não apenas as mulheres precisam pensar que alguma coisa não evidente, a que elas não têm acesso, está de fato acontecendo, mas é necessário fazer com que os próprios noviços sintam que realizaram algo indubitavelmente difícil e (portanto) significativo, mesmo que, para eles também, parcialmente misterioso.

Essa fusão sistemática de revelação e dissimulação, uma das marcas do processo de iniciação, é também levada a cabo em ainda mais um nível com respeito à fórmula litúrgica epônima do ritual. Esse segredo adicional, revelado aos noviços quando chamados a ler, primeiro um lado, depois o outro, do cartão, é que "o vermelho e o negro" (le rouge et le noir) é na verdade, ou igualmente, "o vermelho é o negro" (le rouge est le noir). Diferentemente do enigma do conteúdo das caixas, dá-se aos noviços total acesso a esse segredo. Todavia, aqui também, o jogo de palavras envolvido é perturbadoramente irrelevante: relaciona-se apenas ao ritual e não possui valor algum para além dele. Com efeito, o conteúdo efetivo desse segredo é muito menos importante do que o padrão relacional que sua comunicação implica. Revelado aos noviços, o segredo é então comunicado às mulheres por cada um deles, quando, ao fim de sua iniciação, peço-lhes em voz alta, indicando o cartão sobre a mesa, que proclamem o "mistério" central do rito. Todavia, como est e et são praticamente homófonos, esta revelação consiste, ao mesmo tempo, no veículo da dissimulação do mistério: quando os noviços abertamente anunciam "Le rouge est le noir", as mulheres, que, como eles, foram deliberadamente mal-orientadas antes do início do ritual, não podem senão entender "Le rouge et le noir" 4 .

Os segredos revelados no decorrer de O Vermelho e o Negro, como a maioria dos mistérios iniciatórios, senão todos eles, são calculados para serem parcialmente inacessíveis e/ou profundamente triviais, e, ao mes- 
mo tempo, altamente significativos em termos das configurações interativas implicadas em sua transmissão. O conteúdo substantivo dos segredos - o que está dentro das caixas, as palavras trocadas entre iniciador e noviços, as várias interpretações possíveis do enunciado "Le rouge et/est le noir" - é em si mesmo pouco importante ${ }^{5}$. Eles constituem sobretudo os índices tangíveis, ainda que algo ininteligíveis, da experiência iniciatória, e os padrões de relação discriminativos que os participantes são levados a atuar. Em outras palavras, esses segredos não contêm tanto uma mensagem singular quanto fazem emergir um contexto especial. Especificamente, os participantes se vêem pegos, ao mesmo tempo, em dois modos de dissimulação muito diferentes: em um, o sigilo é abertamente admitido (por exemplo, faz-se as mulheres conscientes do fato de não saberem o que há nas caixas); no outro, é sub-repticiamente ocultado (por exemplo, as mulheres permanecem não conscientes da homofonia et/est, bem como do fato de que os noviços, na verdade, não conhecem realmente o conteúdo das caixas). Como argumentei com respeito à iniciação em geral (Houseman 1993), é a articulação sistêmica desses dois modos contrários do sigilo que fornece o fundamento privilegiado para o que se pode chamar o "trabalho" ritual de O Vermelho e o Negro (Houseman e Severi 1998): de um lado, a designação de agências particulares (os noviços, o iniciador e os iniciados, mas também, potencialmente, as caixas, o cartão etc.); de outro, a emergência de um idioma específico por meio do qual estas agências podem ser expressas (simbolismo).

A condensação ritual de ocultamento declarado e simulação velada dá origem a um contexto ou campo distintivo de comunicação, no qual toda revelação parece gerar a suposição de um nível adicional de sigilo, e mesmo os atos mais triviais podem adquirir um significado novo, secreto e todavia parcialmente indefinido (Barth 1975). Vale sublinhar, contudo, duas coisas. Primeiro, o campo ou contexto distintivo é produzido não como resultado de operações abstratas, mas por meio de experiências corporais carregadas emocional e intencionalmente, propiciadas pela própria ação ritual: o desconforto dos noviços, suas expressões afetivas exageradas ou contidas, suas atitudes ambivalentes diante das mulheres, a frustração e a cumplicidade forçada destas últimas etc., tudo desempenha um papel essencial. Segundo, se essas experiências podem revelar-se marcantes em si mesmas, elas são significativas principalmente por contribuírem para uma dinâmica geral na qual a participação de cada um reforça a dos demais. Em outras palavras, o que conta são menos comportamentos particulares que a configuração relacional de que esses comportamentos formam parte. É essa ordem superior de integração interativa que permite 
à performance ritual absorver "erros" de execução sem se ver por isso corrompida, bem como acomodar considerável variação pessoal (e histórica).

Um dos aspectos mais interessantes desse experimento, revelado pela discussão subseqüente à performance, foi a percepção que os noviços e as mulheres tiveram de sua interação coordenada. Para a maior parte dos noviços que esperavam do lado de fora, o murmúrio feminino soava ameaçador ou lamurioso, impressão acentuada quando, após o silêncio absoluto que saúda a entrada de cada iniciando na sala, as mulheres recomeçam seu burburinho tão logo ele se senta ${ }^{6}$. Se alguns noviços relataram depois terem se sentido confusos quanto à expressão a adotar diante das mulheres, muitos admitiram que, enquanto sentados à mesa, estavam tão concentrados em minhas instruções que mal prestaram atenção ao murmúrio feminino. Todos se surpreenderam ao ouvi-las aclamá-los ou suspirar de alívio coletivamente em resposta a seu fingido grito de dor. Depois de um momento de tensão e desorientação diante do súbito silêncio que se segue (não planejado de minha parte), o noviço dirige-se às mulheres diretamente, desafiando-as, ao proclamar em voz alta (conforme minhas instruções) o mistério central do rito: "Le rouge est le noir" ao que elas respondem coletivamente, "Oui, le rouge et le noir". Após essa impostura final, o noviço é conduzido para trás da cortina, onde deve permanecer de pé, acompanhando pelo som a iniciação dos demais. Os primeiros iniciados determinam, invariavelmente, o tom emocional dominante. Todavia, qualquer que seja a atitude geral adotada por eles em algumas performances é notavelmente solene, em outras mais à vontade -, a maior parte dos noviços se refere a esse período de reclusão coletiva, durante o qual geralmente se congratulam uns aos outros e saúdam os recém-chegados ao grupo, como relaxado e despreocupado. Significativamente, quase todos concordam que, nesse período, o burburinho feminino soava-lhes preocupado e solidário (depois de uma performance, um dos noviços agradeceu às mulheres por seu encorajamento, e vários outros mencionaram os sentimentos de alívio que elas teriam manifestado). Finalmente, quando os noviços emergem triunfais de trás da cortina para encará-las e declaram, conjuntamente, "Le rouge est le noir" - ao que elas só podem responder: "Le rouge et le noir" —, sua ansiedade antes as mulheres e ao ritual em si desaparece, para dar lugar a uma atitude gabola e pretensiosa e a um enfatuamento coletivo ("daquele momento em diante, tornei-me uma pessoa diferente", observou mais tarde um dos homens).

As mulheres, em contraste, experimentando seu próprio burburinho como simultânea ou (para algumas) alternativamente intimidante e en- 
corajador, alegam não perceber as mudanças na atitude dos noviços. Mais que tudo, admitiram depois, sentiam-se simplesmente entediadas e, como mencionei, passam um bom tempo tacitamente consultando-se umas com as outras. Essa sensação de tédio não deve, porém, ser confundida com indiferença, pois oculta algo mais complexo, uma espécie de excitação passiva ou puramente reativa, possivelmente decorrente da situação paradoxal em que elas se encontram. Assim, uma descoberta notável, que emergiu nas discussões subseqüentes à performance, é que quase todas as mulheres - embora extremamente interessadas, como reconheceram, no que se passava com as caixas sobre a mesa - se abstiveram deliberadamente de tentar adivinhar seu conteúdo ou imaginar o que exatamente estava acontecendo do outro lado da sala; uma delas hesitava até mesmo em olhar para a mesa, enquanto a maioria afirmou ter prestado mais atenção aos olhos e face dos noviços do que a suas ações ${ }^{7}$. Em outras palavras, enquanto zelosamente orquestravam seu comportamento conforme as instruções do iniciador e as ações dos noviços - começando, interrompendo e modulando seu murmurar nos momentos certos, suspirando (ou aclamando) e respondendo nas ocasiões corretas - as mulheres subtraíam-se cuidadosamente os meios de adquirir os conhecimentos a que sentiam não ter direito. (Isso era especialmente verdade no caso daquelas que participavam do rito pela segunda vez, cuja maior preocupação era desempenhar adequadamente o papel que lhes fora designado.) Significativamente, algo a que as mulheres prestaram atenção intensa e contínua foi ao grupo de recém-iniciados parcialmente escondido no canto separado pela cortina. De algum modo, era mais fácil para elas espionar e tomar como objeto de especulação os noviços que já haviam passado pelo processo de iniciação, como se essa massa viva, dissimulada e crescente que emergia do processo - uma espécie de entidade iniciática em si mesma - fosse, em parte, uma criação sua. Do ponto de vista feminino, assim, é em uma harmonia afetiva quase perfeita que, ao fim do rito, homens e mulheres põem-se face a face para, juntos, gritar: "Le rouge est/et le noir".

\section{Após o ritual}

Depois de cinco minutos, durante os quais guardo as caixas e o pano branco e recoloco mesas e cadeiras em seus lugares habituais, peço a todos que voltem à sala e se sentem. Para dar início à discussão, peço que relatem por escrito (em um papel que deverão entregar-me) com quem e so- 
bre o que conversaram durante o intervalo, indicando se são homens ou mulheres.

Isso produz freqüentemente resultados muito interessantes. Não só os participantes tendem, pelo menos de início, a formar durante o intervalo grupos sexualmente segregados (uma mulher escreveu: "agora que eles são iniciados, não querem falar conosco"), como também se referem muitas vezes a si mesmos e aos outros em termos de seus papéis rituais ("noviços" vs. "mulheres" ou "não-iniciados" vs. "iniciados"). Um número razoável de pessoas pergunta-se, em voz alta, apesar de eu ter anunciado o encerramento do rito, se este ainda está em andamento. Invariavelmente, algumas mulheres dirigem perguntas aos homens (os homens nunca perguntam nada às mulheres!): "como foi?"; "doeu de verdade?"; "o que há dentro das caixas?"; "o que Houseman disse a você?" e assim por diante. Quase sempre, essas questões são recebidas com tergiversação ou recusa em responder. Réplicas típicas eram: "não podemos falar disso porque somos iniciados" ou "não posso lhe dizer porque você é mulher".

Vejamos alguns exemplos. Várias mulheres perguntaram a um dos homens se ele se sentia diferente desde a iniciação e se sofrera muito, recebendo um "sim" como resposta a ambas as questões. Uma mulher indagou a um outro se realmente sentira dor ou se gritara apenas por ter sido assim instruído. "É claro que doeu", ele retrucou, "do contrário não teríamos gritado". "O que era?", continuou ela. "As mulheres não devem saber". Outro iniciado, interrogado quanto ao conteúdo das instruções dadas pelo iniciador, respondeu: "coloque a mão na caixa vermelha primeiro e depois na caixa preta", não revelando dessa maneira coisa alguma (mas invertendo a ordem das caixas). Outro, para justificar sua recusa, declarou: "as mulheres ficam com a parte fácil; nós fizemos por merecer. Nós, homens, pagamos por isso". Um outro ainda explicou que "eu disse às mulheres que não poderiam entender o que aconteceu porque são mulheres". Um homem relatou uma discussão com duas mulheres e mais dois iniciados em que estes declararam: "não contaremos o segredo nem se soubermos que todos já o conhecem". Uma mulher descreveu a seguinte conversa entre um grupo de homens e um de mulheres: "você se sente mudado?"; "sim, nós sabemos coisas que vocês jamais saberão"; "verdade, nós somos mulheres". Da mesma maneira, uma outra, falando da conversa de um grupo de mulheres com um iniciado, escreveu: "não pedimos que ele descrevesse o ritual, já que as mulheres não têm acesso a esse tipo de segredo". Uma mulher escutou uma outra perguntar a um 
homem o que havia nas caixas; diante do silêncio dele, ela retrucou: "os homens têm seus segredos, e as mulheres têm os seus". Algumas reclamaram o direito de ter sua própria iniciação. Houve também alguns relatos intrigantes, incomuns. Assim, uma mulher escreveu: "conversei com um iniciado, perguntando se ele estava realmente mudado. Ele disse que sim, mas não acreditei". Um homem relatou que, falando em um grupo misto, pedira que nada fosse revelado do ritual, acrescentando que a punição contra isso seria o decepamento das mãos; um outro, que passara pelo processo em uma ocasião anterior, afirmou para um grupo de recéminiciados que "o ritual pode ser bem mais duro"; um outro ainda disse a um grupo de mulheres que na caixa vermelha havia uma cobra.

Em duas ocasiões, depois da performance, um dos iniciados chegou a revelar que dentro da caixa havia "cuspe". Em um caso, porém - no qual o sujeito precedera sua revelação pela afirmação de que "aconteceram coisas sobrenaturais e os noviços foram humilhados" —, isso provocou fortes protestos da parte dos demais que, segundo relataram, se sentiram traídos e mandaram que se calasse (um escreveu que fulano revelara realmente o segredo e que "fazendo isso ele é um mau iniciado e nós [os outros homens] vamos dar-lhe uma surra depois da aula"). No outro caso, as mulheres escutaram o homem, mas várias disseram não ter acreditado no que ele lhes contara ou, mais exatamente, disseram não pensar que o segredo todo fosse só esse (um outro homem que participava da discussão afirmou, porém, ter-se tranqüilizado com a indiscrição do companheiro, pois ele mesmo se indagara sobre o verdadeiro conteúdo da caixa). Certos relatos mostraram que alguns homens, conversando entre si, se perguntavam se tinham atuado corretamente e se a mesma coisa tinha sido dita a todos eles; nenhum, todavia, revelou aos demais o que lhe fora dito.

Segundo certos relatos, algumas mulheres censuraram determinados homens por performances inadequadas: eles não teriam gritado alto o bastante. Uma delas, falando com um iniciando que, por engano, gritara ao colocar a mão na caixa preta, observou: "você foi o único que não conseguiu sequer ser iniciado direito". Em uma performance da qual participaram muitos homens, apenas parte deles foi chamada a passar pelo rito. Os demais, tendo esperado o tempo todo no corredor, pediram que os iniciados lhes deixassem compartilhar do segredo, mas em vão. De modo um tanto surpreendente, muitas mulheres participaram dessa exclusão. Uma delas, por exemplo, indagou a um grupo desses não-iniciados se não se sentiam frustrados, e um deles escreveu: "sou ainda um noviço e, durante o intervalo, conversei com uma das mulheres, e ela me 
disse que eu jamais seria um homem. Ela não me contou nada sobre a iniciação. Um dos iniciados com quem falei explicou-me que eles tiveram de colocar a mão primeiro na água e depois em alguma coisa que machucava". Outro desses não-iniciados, comentando com várias mulheres o "tom sádico do ritual, já que elas aplaudiam a dor dos homens", ouviu delas: "você nunca vai crescer". Um terceiro escreveu: "não falei com os iniciados, mas ouvi com muita atenção".

Nem todos os relatos são reveladores (há casos em que os participantes falaram de outros assuntos, e alguns indicam simplesmente "conversei com um homem/mulher"). Porém, aqueles que se referem a conversações sobre O Vermelho e o Negro se orientam claramente na mesma (e prevista) direção. Segredos são preservados e a existência de mistérios incomunicáveis é ativamente sugerida. Mais ainda, isso é feito, freqüentemente, de maneira que a suposta autoridade dos iniciados e a suposta ignorância dos não-iniciados sejam sustentadas pela conivência de ambos os sexos. Finalmente, uma quantidade notável de relatos atesta que o conhecimento secreto deve ser legitimamente recusado às mulheres simplesmente porque são mulheres.

Como sugeri na introdução, reações como estas últimas são mais significativas do que pode parecer. Os participantes podem não ter uma idéia clara da exata natureza do ritual ou do que ele "diz" sobre homens ou mulheres, como tampouco o teriam do que "diz", por exemplo, sobre o vermelho e o negro. Contudo, interpretações precisas concernentes a tais problemas são, eu argumentaria, irrelevantes, opcionais e largamente idiossincráticas. Mais significativo é o modo como as relações discriminativas atuadas no contexto altamente particular e artificialmente construído em que consiste a performance ritual parecem ganhar vida própria. Isto é, parecem adquirir aquela qualidade auto-evidente, naturalizada, que é a marca da interação cotidiana.

A performance ritual fornece aos participantes uma experiência excepcional por meio da qual discursos e comportamentos consonantes com a configuração relacional realizada durante a performance podem ser mais facilmente entretidos fora dela. Os participantes agem e falam de uma maneira que implica (para eles e para outros) que, por exemplo, sigilo, sofrimento, comedimento, silêncio, conhecimento e masculinidade, de um lado, e exclusão, medo, preocupação, ignorância e feminilidade, de outro, associam-se não de maneira externa e contingente, mas interna e constitutiva.

Sob esse ponto de vista, a lógica interativa que governa as conversas travadas no intervalo é altamente significativa. Não que as mulheres te- 
nham atazanado os novos iniciados até que estes se vissem forçados a rejeitar seus avanços ou a conceder-lhes algumas migalhas de informação. Antes, são os recém-iniciados que se exibem diante delas, provocando sua curiosidade, precisamente para poder rejeitar suas perguntas. Não são as mulheres que se sentem movidas por uma necessidade imperativa de saber, mas os homens que solicitam delas provas de sua frustrada ignorância. Com efeito, o que para os homens consistiu em um ato de exclusão central para a distintividade de seu status, para boa parte das mulheres envolveu uma cumplicidade tolerante diante da necessidade visível dos novos iniciados em ostentar a posse de segredos largamente triviais. Em outras palavras, O Vermelho e o Negro parece encorajar homens e mulheres a definir sua identidade sexual de modo interdependente, em termos de suas respectivas experiências rituais. Dessa maneira, as ações e palavras dos participantes fora do quadro do rito expressam seu compromentimento não com "crenças" abstratas, mas com a realidade das relações que atuam ritualmente. Em termos de eficácia, suspeito que não se possa esperar mais que isso de qualquer evento cerimonial.

Deixem-me tentar ser o mais claro possível. O Vermelho e o Negro, como os rituais em geral, não cria nada ex nihilo: relações desiguais entre homens e mulheres na cultura ocidental moderna são tanto uma premissa quanto um resultado de sua performance. Todavia, o que esse ritual faz é conferir nova vida à discriminação sexual, expressando-a no idioma da experiência, amplamente irrefutável ainda que difícil de definir, propiciada pela performance. Certas afirmações ou comportamentos que, em circunstâncias ordinárias, podem parecer inaceitáveis ou bizarros para quase todos os participantes - alegações explícitas da superioridade dos homens sobre as mulheres - tornam-se, como resultado da participação em O Vermelho e o Negro, mais plausíveis para todos os envolvidos. Em alguns casos, essas afirmações ou atos discriminatórios eram realizados, pelo menos parcialmente, como brincadeira: O Vermelho e o Negro autorizava os participantes - na sua maioria, estudantes de antropologia - a "brincar" de iniciado e não-iniciado. Todavia, essa ludicidade, que ocorre também em iniciações para valer, de modo algum reduz os efeitos muito reais desse comportamento: antagonismo sexual, solidariedade masculina, autocensura cúmplice das mulheres, atitudes preconceituosas perante os não-participantes do ritual e assim por diante. Em outras palavras, o discurso e conduta discriminatórios favorecidos pela participação na performance, uma vez levados a cabo, adquirem por si mesmos uma realidade comunicativa, ancorada na própria experiência ritual: para realmente compreender como essas afirmações e atos são pos- 
síveis, bem... você tem de passar por O Vermelho e o Negro. Desse ponto de vista, pois, a performance ritual procede antes por subtração que por adição, em face das premissas da interação cotidiana. Todavia, como um modo distintivo de transmissão cultural, o que ela faz é imensamente significativo: veicula valores e idéias recorrentes sob a forma de atuações [enactments] auto-referenciais, altamente memoráveis e emocionalmente carregadas.

\section{Discussão}

O Vermelho e o Negro serve também a um propósito pedagógico. Assim, tendo coletado os relatos dos participantes, proponho-lhes uma discussão geral do rito. Esta, invariavelmente, toma várias direções ao mesmo tempo. Tentarei aqui abordar temas que conduzem a questões mais gerais a propósito de algumas das implicações da ação ritual.

Um traço saliente, já mencionado, é a facilidade com que a performance é capaz de acomodar tropeços e variações. Um homem, por exemplo, gritou quando pôs a mão na caixa preta, enquanto um outro, tendo entendido que deveria expressar, em lugar de reprimir, seus sentimentos quando tocasse o "cuspe", deu vazão a seu nojo em alto e bom som. Alguns agarraram o cacto que estava na caixa vermelha de tal maneira que fui obrigado a pedir várias vezes que o largassem. Uma boa parte dos homens revelou na discussão não ter se dado conta de que "o vermelho é o negro" estava escrito no verso do cartão, enquanto alguns deles admitiram ter estado tão nervosos a ponto de não lembrar o que eu lhes dissera. E, é claro, há considerável variação no modo como noviços e mulheres desempenham seus papéis: alguns homens gritam mais convincentemente que outros, algumas mulheres são mais aplicadas que outras em seu murmurar, e assim por diante. Há, é forçoso imaginar, um limite quanto ao grau de desvio do protocolo estabelecido que a performance pode suportar. Todavia, surpreendi-me diante de quão pouco essas disparidades perturbaram o ritual ou comprometeram sua aparente eficácia. Sugiro que isto se deva, pelo menos em parte, ao fato de que performances rituais se baseiam menos em uma seqüência ordenada de comportamentos (isto é, em um script) do que são orientadas para a geração de padrões interativos cujas qualidades sistêmicas tendem a cancelar inevitáveis irregularidades individuais ${ }^{8}$. Assim, por exemplo, é interessante observar o grau em que a concentração dos noviços e a das mulheres são interdependentes. Em uma ocasião em que estas, em lugar de murmurarem pa- 
ra si mesmas, começaram a cochichar sobre isso ou aquilo outro, a concentração dos homens foi imediatamente quebrada: eles passaram a olhar para elas em vez de para mim e a performance adquiriu as propriedades de um jogo ou espetáculo.

No mesmo sentido, a discussão revelou também que uma performance ritual bem-sucedida apóia-se menos sobre a convergência das disposições e motivações dos participantes que sobre a coordenação sistêmica de suas ações conforme padrões relacionais explícitos. Não apenas noviços e mulheres têm, individualmente, sentimentos muito diferentes sobre o que estão fazendo, como suas interpretações da experiência dos demais é freqüentemente equivocada. Assim, por exemplo, enquanto os noviços percebiam as mulheres como alternativamente queixosas, ameaçadoras, solidárias e aliviadas, estas se sentiam predominantemente confusas e entediadas. Isso em nada diminui a eficácia do ritual.

Uma considerável variabilidade caracteriza também as interpretações simbólicas propostas pelos participantes. Lembro que tentei reduzir ao mínimo o simbolismo explícito do rito. Para vários participantes, entretanto, certos aspectos da performance tornam-se objeto de especulação hermenêutica, uma vez que suas próprias ações e as dos demais lhes aparecem como dotadas de significado. Morte e sangue são às vezes evocados em conexão com o preto e o vermelho, respectivamente; uma pessoa afirmou que essas cores eram particularmente salientes, culturalmente significativas, de tal modo que, se as caixas fossem azul e amarela, por exemplo, o ritual não teria "funcionado" tão bem. Durante o intervalo, uma mulher perguntou a um noviço "que frase o iniciador pronunciou quando você pôs a mão na [dolorosa] caixa vermelha? Ele disse: 'são as mulheres', não foi?". Vários homens, por sua vez, especularam sobre a oposição estrutural entre líquido e viscoso (caixa preta), de um lado, e seco e espinhoso (caixa vermelha), de outro. Finalmente, o que me pareceu muito interessante, uma mulher que participava pela segunda vez escreveu: "enquanto eu estava murmurando, notei que tudo era vermelho ou preto na sala, o modo como Houseman estava vestido, mas tabém o fato de que eu tinha comigo uma pasta vermelha, duas canetas vermelhas e uma preta" 9 . Para mim, este último relato ilustra perfeitamente como o simbolismo ritual, um idioma prolixo mais que um código preciso, opera: não significando uma mensagem especial, mas indicando um contexto privilegiado.

As principais características de O Vermelho e o Negro são simplesmente o que é dado aos participantes experimentar: a complementaridade antagonística de homens e mulheres, a associação do preto e do ver- 
melho, a interdependência de conhecimentos ocultados e declarados, a justaposição de silêncio e ruído e assim por diante. O que torna "simbólicos" esses traços não é a existência de significados ocultos particulares bem definidos, mas o fato de eles converterem-se em veículos auto-referenciais para designar o sistema de relações atuado no decorrer do rito e as agências que esse sistema implica. A maior parte dos participantes, especialmente os noviços, sente que ter passado por O Vermelho e o Negro fez uma diferença, mas tem dificuldades de explicar em que esta exatamente consiste. Aqueles aspectos do rito que permitem a eles referir-se a essa diferença em palavras ou atos, antes que seja necessário apelar mais uma vez para o venerável tributo à eficácia da iniciação - "é preciso experimentar para compreender" - , constituem o simbolismo do ritual.

Desse ponto de vista, o traço simbólico mais saliente de O Vermelho e o Negro, sua "armadilha mental" [thought-trap] (Smith 1979) mais persuasiva, é indubitavelmente o padrão de sigilo que gera. De modo talvez nada surpreendente, os participantes relutam em falar de tais assuntos, e, para ser franco, eu também. Assim, em lugar de expor cruamente as várias imposturas que o ritual envolve, faço algo bem diferente. Revelando alguns segredos (como a homofonia "e/é" ou a suposta presença de saliva na caixa preta), sugiro a existência de outros (como a presença de alguma coisa, além de saliva, na mesma caixa, ou o conteúdo da caixa vermelha) e, ao desvelar esses novos segredos, insinuo a existência de níveis de dissimulação ainda por serem revelados (como minhas instruções aos noviços ou o que acontece no canto atrás da cortina). Esse processo de "secreção" [secretion] (Zempléni 1976) implica freqüentemente jogar com a diferença entre a posição do experimentador e a dos demais participantes, assim como entre aquela dos homens e a das mulheres. Por exemplo, algumas vezes, em plena discussão de um tema totalmente diferente, após ter previamente admitido que, ao contrário do que os noviços tinham sido levados a acreditar, não havia na caixa saliva alguma, anuncio que vou, agora, revelar o "verdadeiro" segredo do ritual, o qual apenas os homens serão capazes de compreender. Mostro então a todos, por alguns segundos, um ovo branco, antes de recolocá-lo no bolso. Alguns homens, que experimentaram a viscosidade do conteúdo da caixa preta, exibem sinais de compreensão (mas nada dizem), enquanto as mulheres, desprovidas da mesma experiência, não percebem a conexão (mas parecem conscientes de estar perdendo alguma coisa). Estabelecendo assim várias camadas de sigilo, cada vez mais obscuras, segredos sobre segredos sobre segredos, meu objetivo é provocar - como quando, no início, ofereci um histórico obviamente espúrio para O Vermelho e o Negro - uma certa confu- 
são na mente dos participantes. Na abertura do experimento, como eu disse, essa confusão é introduzida para solapar o quadro de "brincadeira" que ameaça tornar-se dominante. Entretanto, a mistificação que instigo ao final serve a um propósito inteiramente distinto. Os ritos de iniciação envolvem, tipicamente, um processo demorado, por meio do qual os iniciados são progressivamente devolvidos a suas vidas diárias; várias proibições e prescrições, por exemplo, persistem longamente após o término da iniciação em si. De maneira muito semelhante, componho e ao mesmo tempo diluo os aspectos sigilosos de O Vermelho e o Negro, de modo a delimitar o quadro ritual o máximo possível. Reproduzindo, sob o manto de uma explicação erudita, o padrão interativo atuado no decorrer da performance, tento estender, tão gradual e suavemente quanto possível, certos traços essenciais do contexto ritual para o domínio da interação cotidiana, fazendo durar a eficácia do rito o máximo possível. Assim, sempre guardo comigo pelo menos um segredo: por exemplo, nunca revelo aos participantes que o ovo que lhes mostrei é falso.

\section{(Auto-)Reflexão}

Mantendo o tom confessional da seção precedente, gostaria de arrematar este relato considerando brevemente a eficácia ritual desse experimento para o experimentador. Não se trata de mera autocomplacência, mas de levantar uma questão raramente enfrentada no estudo dos ritos de iniciação, a saber: o que torna o ritual eficaz para os iniciadores? Evocar a força da "tradição" parece-me envolver uma petição de princípio e, de qualquer forma, seria dificilmente aplicável no caso presente. Como sugeri, os aspectos interativos de O Vermelho e o Negro podem nos ajudar a dar conta de como esta performance adquire uma significância particular para os noviços e para as mulheres, as quais não gozam de pleno acesso aos acontecimentos. Contudo, a situação é com certeza bem diferente para o iniciador que, por assim dizer, tem todas as cartas na mão. Em outras palavras, o que me impediria, como iniciador, de experienciar O Vermelho e o Negro como um caso de pura e simples mistificação, ou intimidação, uma manipulação inocente de outrem em nome de uma nobre causa (a teoria antropológica)? Como mostra minha discussão dos segredos do ritual após sua realização, hesito em desmascarar completamente O Vermelho e o Negro. Por quê?

Argumentei alhures (Houseman 2002) que, para os oficiantes, a eficácia da iniciação (e da ação ritual em geral) deriva, essencialmente, não 
do manobrar interativo dos participantes humanos, como noviços ou mulheres, mas da manipulação de não-pessoas: objetos, encantamentos, animais etc. Essas operações de manipulação, que chamo "simulações" para distingui-las de "dissimulações" (as quais envolvem a coordenação das ações de outros participantes), agem no sentido de estabelecer, na mente dos oficiantes (e de outros), uma relação circular entre as atividades rituais que eles empreendem e sua aptidão para empreendê-las. Essas operações, sugeri, ocorrem normalmente durante a preparação para o rito ou subseqüentemente a este, isto é, elas estão distanciadas, por assim dizer, de um grau da experiência ritual compartilhada pelos demais participantes.

Parece-me que algo desse tipo ocorre em O Vermelho e o Negro. Como um aluno observou, a enorme importância que atribuo à impostura em torno da homofonia "é/e" é, em si mesma, digna de nota, a despeito do fato de que tal mistério supostamente supremo só é captado por alguns dos noviços (as mulheres, é claro, por princípio ignoram até mesmo sua existência). Talvez não seja por acidente que minha maior preocupação incida sobre aquilo que consiste no único traço litúrgico explícito da performance. Confesso que, algo perversamente, a ignorância desse segredo em que permanecem muitos dos noviços funciona para justificar, e não para invalidar, essa preocupação, como se eu estivesse convencido de que é preciso realmente passar várias vezes pela iniciação para realmente compreender o sentido do ritual.

Meu cuidado em utilizar, de performance para performance, o mesmo aparato material, traduz, talvez de modo ainda mais óbvio, a mesma convicção: as mesmas caixas, o mesmo pano branco (cuidadosamente passado a ferro na noite anterior), o mesmo cacto e assim por diante. Quando, por exemplo, ao fechar-me no banheiro para os preparativos, vejo no fundo da caixa preta os restos de clara de ovo das ocasióes anteriores, sinto-me curiosamente reconfortado. Também sinto ser adequado trajar-me inteiramente de preto e vermelho no dia da performance (e não sou o único: uma mulher que já passara pelo ritual apareceu na ocasião igualmente vestida nessas cores). Finalmente, minha roupa de baixo é sempre preta. Este último elemento é especialmente digno de atenção. Não há dúvida de que isso me titila porque estabelece mais um nível de sigilo do qual ninguém - salvo você, gentil leitor - tomará conhecimento. Todavia, o que cabe enfatizar a respeito desses preparativos privados, especialmente a roupa de baixo preta, é o fato de que, da perspectiva dos demais participantes, eles são totalmente supérfluos. Qualquer que seja a eficácia de O Vermelho e o Negro, ela seguramente independe da cor 
de minhas cuecas. Sou forçado a concluir que, se executo essas operações, é porque elas tornam o ritual mais eficaz para mim, o iniciador. Em particular, é justamente porque esse comportamento preparatório é tão desnecessário do ponto de vista dos demais participantes, e portanto não redutível a uma dissimulação induzida artificialmente, que o ritual e o meu papel nele adquirem, para mim, um significado adicional (ainda que algo obscuro): é isso que me faz, e não aos outros, iniciador. Minhas cuecas tornaram-se a pedra de toque tangível de meu próprio comprometimento com o fato de que algo de "sério" está se passando.

Ora, não "creio", nem por um segundo, que O Vermelho e o Negro seja um verdadeiro rito de iniciação, ou que eu seja um verdadeiro oficiante. Ainda assim, ao repetir esses gestos tais como os executei antes em retrospecto, estou certo de que mesmo da primeira vez pensei que já os executara antes (cf. Casajus 1993) — sinto-me mais próximo do sentido do ritual (não do experimento). Eles simplesmente parecem ser a coisa certa a fazer; ou melhor, como sugerem as performances prévias, eles parecem funcionar.

Em suma, suspeito de que, como o xamã relutante de Lévi-Strauss (1958), por força de organizar esse maldito O Vermelho e o Negro, acabei enforcando-me em minha própria corda.

\section{Nota final}

Em respeito à praxe acadêmica, deixem-me concluir considerando certas questões eventualmente levantadas pela natureza "pública", "iniciadorevela-tudo", do presente relato. Tudo terá sido realmente revelado? Uma das coisas que vim me esforçando por demonstrar é, justamente, quão indeterminada é tal questão. Como já deveria estar claro, a existência de segredos substantivos particulares, no contexto da performance de O Vermelho e o Negro, vê-se progressivamente ofuscada pela presunção de sigilo gerada por meio do padrão interativo no qual os participantes (eu incluído) se acham envolvidos. De fato, na medida em que o experimento pode ser dito "funcionar" como um rito de iniciação, ele envolve algum grau de circularidade recursiva na qual a dissimulação dá origem a uma forma relacional específica que, por sua vez, cria condições para mais dissimulação. Um de meus objetivos ao realizar, discutir e pôr no papel esse experimento foi esclarecer em que consiste, afinal, um sistema auto-organizado. Este sistema, que tomo como constituindo a essência do processo iniciatório, é fortemente determinado do ponto de vista interacional, mas 
eminentemente aberto do ponto de vista representacional: como os fenômenos fractais, ele implica a possibilidade de níveis de significado sempre novos a serem explorados. Nesse sentido, pode-se presumir que restam sempre segredos adicionais, inarticulados, que só precisam ser pensados por mim (ou por outros participantes) para que cobrem existência, menos como "coisas" a serem escondidas ou reveladas do que como premissas a serem reiteradas e levadas a efeito. Em suma, embora eu tenha efetivamente revelado tudo em que pude pensar, não é possível, por definição, esgotar os segredos de O Vermelho e o Negro.

Uma segunda consideração, relacionada à anterior, concerne ao impacto que o presente artigo pode vir a ter sobre performances futuras. Esta é uma questão empírica difícil de ser respondida. Com base nas reações daqueles que passaram por O Vermelho e o Negro várias vezes e, portanto, participaram também de sua subseqüente desmontagem, suspeito que o efeito será pequeno: a atuação coordenada de relações tem suas próprias razões sistêmicas que a razão ignora. Quem sabe, haverá sempre por parte dos participantes a quantidade certa de envolvimento pessoal para que se sintam aprazivelmente interessados e surpresos. Meu objetivo, afinal, não é iniciar as pessoas, mas comunicar a elas algo sobre a iniciação. A pessoa mais afetada provavelmente serei eu mesmo, uma vez que descrever O Vermelho e o Negro de modo tão exaustivo me compromete de um modo que destoa da postura iniciatória e mistificadora que inevitavelmente assumo durante a organização desse evento. Por outro lado, no calor da performance, será bastante fácil para mim passar por cima do fato de que um dia escrevi este texto (se alguém perguntar, digo que tudo era verdade, a não ser...). Contas feitas, se minha carreira como iniciador-aprendiz ainda não está totalmente encerrada, talvez esteja chegando a hora de entregar o chapéu para outros. Em todo caso, há algum tempo venho acalentando a idéia de passar a outra coisa - ao sacrifício, por exemplo...

Michael Houseman ensina na École Pratique des Hautes Études (EPHE), em Paris, e é autor, com Carlos Severi, de Naven or the other self: a relational approach to ritual action (1998). 


\section{Notas}

* Alguns resultados desta pesquisa foram apresentados no Grupo de Trabalho de Antropologia Social Comparativa (EHESS, Paris) e no seminário "Working Papers", do Centro de Pesquisa de Sistemas de Pensamento Africano (EPHE/ CNRS, Paris). Gostaria de agradecer aos participantes por suas úteis sugestões. Estou também em dívida com Marika Moisseeff, Don Handelman, Galina Lindquist e os pareceristas anônimos de Mana, por comentários a uma versão anterior, e, acima de tudo, com os vários co-experimentadores que se dispuseram a compartilhar suas impressões comigo.

1 Para uma apresentação mais completa dessa abordagem do ritual, ver Houseman (2003a).

2 Ensino na seção de "Ciências Religiosas" da École Pratique des Hautes Études (EPHE) em Paris, uma instituição de pós-graduação que (como todas as universidades francesas) é gratuita e geralmente aberta a ouvintes externos. Na ausência de um currículo predeterminado, a única condição é que eu não me repita de um ano para outro. Assim, alguns alunos assistem meu curso por vários anos, de modo que alguns deles viram-se diversas vezes envolvidos no rito. Até agora, organizei $\mathrm{O}$ Vermelho e o Negro cinco vezes nos últimos três anos.

3 Este é, suspeito, um problema geral, pois enquanto jogos e outros exemplos explícitos de atividade lúdica ocorrem comumente no interior dos rituais sem colocar em questão sua seriedade, o status de uma atividade ritual que partiria das premissas do jogo [play] parece mais problemático (cf. Houseman 2002 para uma ilustração do "fingir que se está fingindo" em um contexto ritual; cf. Houseman 2003b para uma discussão das suposições pragmáticas que governam o jogo, o ritual, o espetáculo e a interação ordinária).

4 De maneira a tornar esse mal-entendido dissimulado ainda mais explícito, nas duas últimas performances de O Vermelho e o Negro incluí o seguinte diálogo entre os noviços atrás da cortina e as mulheres:

Noviços: Le rouge est le noir.

Mulheres: Oui, le rouge et le noir.

Noviços: Non, le rouge est le noir.

Mulheres: Le rouge et le noir (interpretável pelos noviços como "le rouge est le noir").

Noviços: Oui, le rouge est le noir.

Do ponto de vista dos noviços, esse diálogo, ao menos potencialmente, faz todo sentido, enquanto para as mulheres não faz nenhum. Centrado na frase "não, o vermelho é o negro", o diálogo é construído de tal maneira que noviços e mulheres são levados a assumir abertamente uns o papel dos outros, enquanto ao mesmo tempo confirmam veladamente (para os noviços) sua separação. 
5 Um aluno, que filmara a performance, enviou-me depois o vídeo com um conjunto de "instruções" paradoxais que incorporavam ainda uma outra interpretação, que não ocorrera a mim nem a ninguém: "le rouge hait le noir" (o vermelho odeia o negro)!

6 Uma fonte adicional de condensação relacional é fornecida por aqueles homens que já participaram do ritual. Eles são instruídos a permanecer de pé atrás dos noviços (sentados à mesa) e tocar suas costas tão levemente quanto possível. Esse comportamento é interpretado pelos noviços, pelas mulheres que os observam e pelos não-iniciados como, ao mesmo tempo, protetor e intimidativo.

7 A concentração das mulheres no rosto dos noviços é particularmente interessante na medida em que, enquanto estes se percebem como estando plenamente à vista delas, muitas mulheres assinalaram o fato de que minha cabeça e corpo bloqueavam parcialmente sua visão.

8 As propriedades sistêmicas da performance ritual, acentuando o ajuste dos participantes aos ritmos e efeitos expressivos implicados por suas ações coordenadas, explicam também alguns traços emergentes e imprevistos de O Vermelho e o Negro, como o súbito silêncio das mulheres após o grito do noviço.

9 O único fragmento de "simbolismo" adotado espontaneamente por quase todos, e que, significativamente, nada tinha a ver com o ritual per se, resultou do erro que cometi uma vez ao me referir à cortina que escondia os recém-iniciados (por acaso, uma cortina verde) como "a floresta". 


\section{Referências bibliográficas}

BARTH, Frederick. 1975. Ritual and knowledge among the Baktaman of New Guinea. Oslo: Norwegian Universities Press.

BELL, Catherine. 1992. Ritual theory, ritual practice. New York: Oxford University Press.

BOURDIEU, Pierre. 1986. "Les rites comme actes d'institution". In: P. Centlivres e J. Hainard (eds.), Les rites de passage aujourd'hui. Lausanne: Éditions l'Age d'Homme. pp. 206215.

CASAJUS, Dominique. 1993. "Figures paradoxales dans quelques analyses de rituals". In: L. Scubla (ed.), Epistemologie et anthropologie: autoréférence, identité et altérité. Paris: CREA/École Polytechnique. pp. 141-157.

COHEN, Yehudi A. 1964. “Establishment of identity in a social nexus: the special case of initiation ceremonies and their relation to value and legal systems". American Anthropologist, 66:529-552.

HANDELMAN, Don. 1998 [1992]. Models and mirrors: towards an anthropology of public events (2a ed.). New York: Berghahn Books.

HOUSEMAN, Michael. 1993. "The interactive basis of ritual effectiveness in a male initiation rite". In: P. Boyer (ed.), Cognitive aspects of religious behaviour. Cambridge: Cambridge University Press. pp. 207-224.

. 2000. "La percezione sociale delle azioni rituali". Ethnosistemi, 7:6774.

.2002. "Dissimulation and simulation as modes of religious reflexivity". Social Anthropology, 10(1):7789. .2003a. "Relationality". In: J. Kreinath, J. Snoek e M. Stausberg (eds.), Theorizing rituals: classical topics, theoretical approaches, analytical concepts, annotated bibliography. Leiden: Brill Publications.

. 2003b. "Vers un modèle anthropologique de la pratique psychothérapeutique". Thérapie Familiale. . e SEVERI, Carlo. 1998. Naven or the other self: a relational approach to ritual action. Leiden: Brill Publications.

LÉVI-STRAUSS, Claude. 1958. "Le sorcier et sa magie". In: Anthropologie structurale. Paris: Plon. pp. 183-203. .1971. L'homme nu. Mythologiques IV. Paris: Plon.

SMITH, Pierre. 1979. "Aspects de l'organisation des rites". In: M. Izard e P. Smith (eds.), La fonction symbolique. Paris: Gallimard. pp. 139170.

ZEMPLÉNI, Andras. 1976. "La chaîne du secret". Nouvelle Revue de Psychanalyse, 14:312-324.

. 1991. "Initiation". In: P. Bonte e M. Izard (eds.), Dictionnaire de l'ethnologie et de l'anthropologie. Paris: Presses Universitaires de France. pp. 375-377. 
Resumo

Este artigo trata da performance de um rito de iniciação inventado pelo autor, realizado como um experimento para pensar certos traços recorrentes da ação ritual e, em particular, da iniciação (masculina). O ritual em questão, $\mathrm{O}$ Vermelho e o Negro, foi planejado para consistir essencialmente, se não exclusivamente, em um padrão específico de interação: O Vermelho e o Negro não pertence a nenhuma tradição cultural reconhecível, não envolve quase nenhum simbolismo explícito, suas "crenças" subjacentes são abertamente despropositadas, suas qualidades cênicas mínimas e não se pode atribuir a ele praticamente nenhuma função social. Um dos objetivos do exercício é explorar e fundamentar uma abordagem relacional da análise do ritual na qual este é visto como atuação de relações específicas. Entre os temas discutidos estão os do enquadramento, da simulação, do sigilo, da imposição de sofrimento, da eficácia cerimonial, da condensação ritual e do complexo jogo de perspectivas internas e externas ao grupo.

Palavras-chave Ritual, Iniciação, Interação, Sigilo, Eficácia Ritual
This article reports on the performance of an initiatory rite of the author's invention, undertaken as a practical experiment for thinking about certain recurrent features of ritual action and, specifically, of (male) initiation. The initiatory ritual in question, The Red and the Black, was designed to consist essentially if not solely in a particular pattern of interaction: it belongs to no recognizable cultural tradition, it involves almost no explicit symbolism, its underlying beliefs are overtly preposterous, its scenic qualities are minimal, and little if any social function can be attributed to it. One of the goals of this exercise was thus to explore and substantiate a particular relational approach to the analysis of ritual performance in which the latter is envisaged as the enactment of special relationships. Framing, simulation, secrecy, imposed suffering, symbolism, ceremonial efficacy, ritual condensation and the complex interplay of in-group and out-group perspectives, are among the issues that are illustrated and discussed.

Key words Ritual, Initiation, Interaction, Secrecy, Ritual Efficacy 